\title{
Abnormalities of visual function in hereditary motor and sensory neuropathy
}

\author{
William P. Honan ${ }^{\mathrm{a}, \mathrm{b}}$, James R. Heron ${ }^{\mathrm{a}, \mathrm{b}}$, David H. Foster ${ }^{\mathrm{c}}$, Graham K. Edgar ${ }^{c}$ \\ and Mark O. Scase ${ }^{\mathrm{c}}$ \\ ${ }^{a}$ Department of Neurology, North Staffordshire Royal Infirmary, Princes Road, Hartshill, Stoke on Trent ST4 7LN, UK, \\ ${ }^{b}$ School of Postgraduate Medicine and Biological Sciences, University of Keele, Thornburrow Drive, Hartshill, Stoke on Trent ST4 7BQ, UK, \\ and ${ }^{c}$ Department of Communication and Neuroscience, University of Keele, Keele, Staffs. STS SBG, UK
}

(Received 12 September 1992)

(Revised, received 11 August, 1992)

(Accepted 20 August 1992)

Key words: Hereditary motor and sensory neuropathy; Visual evoked potentials; Temporal contrast sensitivity; Colour vision

Summary

Visual function was studied in a group of 15 patients with hereditary motor and sensory neuropathy (HMSN). Psychophysical measures of luminance and chromatic threshold and temporal contrast sensitivity were undertaken, together with visual evoked potentials (VEPs), visual fields and clinical neuro-ophthalmological examination. A patchy loss of visual function was found in individual cases of HMSN. In the group analysis there was evidence of a selective loss of luminance threshold and temporal contrast sensitivity at low temporal frequencies; the VEP P100 latency was not significantly prolonged. The losses of visual function in HMSN were discussed and compared with visual losses in multiple sclerosis, which had been detected using identical experimental techniques.

\section{Introduction}

Sporadic cases of optic atrophy associated with hereditary motor and sensory neuropathy (HMSN) have been reported (Schneider and Abeles 1937; Hoyt 1960), although the incidence of optic atrophy in large series of HMSN cases is very low (Brust et al. 1978; Harding and Thomas 1980). The majority of necropsy reports on HMSN in which the central nervous system has been examined have reported degeneration of the dorsal columns (Hughes and Brownwell 1972; de Recondo 1975). In an isolated report on pathology of the optic nerve, Alajouanine et al. (1967) noted demyelination of the optic nerve in a case of HMSN.

Evidence of more frequent subclinical involvement of the visual pathway has been suggested by the detection of abnormal visual evoked potentials (VEPs) in cases with HMSN: Tackmann and Radu (1980) found abnormal VEPs in 5/9 cases and Bird and Griep

Correspondence to: Dr. J.R. Heron, Department of Neurology, North Staffordshire Royal Infirmary, Stoke on Trent ST4 7LN, UK. Tel.: (0782) 715444, ext. 4343.
(1981) reported 4/25 cases with abnormal VEPs. Gjerstad el al. (1988) measured VEPs in 11 cases with HMSN and found no significant differences in mean P2 latency between the control and HMSN groups; however, the study did show that cases with HMSN type I had significantly prolonged P2 latencies compared to cases with HMSN type II. Carroll et al. (1983), in a more detailed study, found some evidence of abnormal VEPs in $7 / 15$ cases with HMSN, but there was poor correlation between these electrophysiological abnormalities and clinical neuro-ophthalmological assessment which included visual fields, funduscopy and measurement of colour vision using the Hardy-Rand-Rittler A.O. pseudo-isochromatic plates.

In the present study on HMSN, a broad range of visual functions was assessed including psychophysical measures of luminance and chromatic threshold and temporal contrast sensitivity (de Lange attenuation characteristic), together with VEPs, visual fields and clinical neuro-ophthalmological examination. The experimental protocol was identical to that in a study of multiple sclerosis (MS) (Honan et al. 1990), which enabled a direct comparison to be made between abnormalities of visual function in HMSN and MS. 


\section{Materials and methods}

\section{Apparatus and stimuli}

The psychophysical measures were obtained using a modified visual perimeter (Foster et al. 1985; Honan et al. 1990), which was designed to produce a small central stimulus field, superimposed on a concentric auxiliary (or surround) conditioning field and a larger background field. The subject was seated in a chair with a firm headrest, $1.2 \mathrm{~m}$ from the perimeter screen. An artificial pupil was not used. The tests were performed monocularly; the other eye was occluded with a patch. Subjects were examined for refractive errors and either used their own spectacles or a suitable lens was inserted into an eyepiece in front of the eye.

For luminance-threshold measurements the stimulus consisted of a $0.25^{\circ}$ diameter, circular spot of white light of duration $200 \mathrm{msec}$. For chromatic-threshold measurements, this stimulus was filtered by a "red" long-pass filter with a half-height cut on wavelength of $622 \mathrm{~nm}$. The steady, circular auxiliary field had a diameter of either $0.25^{\circ}$ or $1.25^{\circ}$, referred to as "small" and "large" respectively; its luminance was $1.85 \mathrm{log}$ $\mathrm{cd} \cdot \mathrm{m}^{-2}$. The auxiliary field influenced the balance of chromatic and luminance responses to the stimuli (Foster et al. 1985). The larger background field, which controlled the overall state of retinal adaptation, was circular with a diameter of $20^{\circ}$; its luminance was held constant at $1.42 \log \mathrm{cd} \cdot \mathrm{m}^{-2}$. There were two separate experimental conditions: the white stimulus on the large auxiliary field gave a luminance threshold; the red stimulus on the small auxiliary field gave a chromatic threshold (Foster 1981; Foster and Snelgar 1983). Each threshold determination was based on 45 stimulus trials, including 5 randomly inserted "empty" trials, containing no stimulus flash, to provide an assessment of subject bias. The luminance level of stimulus was adjusted, by a microcomputer, according to a hybridadaptive technique (Taylor and Creelman 1967; Hall 1981). The responses were analysed using a computerbased technique which fitted a cumulative Gaussian frequency-of-seeing curve to each set of data (Foster and Bischof 1987). The stimulus threshold was defined as the level at which the stimulus was seen on $50 \%$ trials.

For measurement of the de Lange attenuation characteristic the stimulus was a sinusoidally-temporallymodulated but spatially uniform, circular spot of yellow (peak emission wavelength $584 \mathrm{~nm}$ ) light, $0.25^{\circ}$ in diameter. The stimulus duration was $2 \mathrm{sec}$ and its mean luminance was $2.0 \log \mathrm{cd} \cdot \mathrm{m}^{-2}$. The surround field had outer diameter $1.25^{\circ}$, inner diameter $0.25^{\circ}$ and a constant luminance of $2.0 \mathrm{log} \mathrm{cd} \cdot \mathrm{m}^{-2}$. The larger background field was identical to that used for the luminance and chromatic threshold measurements. Temporal contrast thresholds were obtained at $2 \mathrm{~Hz}$ and then at $3 \mathrm{~Hz}$ intervals up to $29 \mathrm{~Hz}$. At the end of this series of measurements, the temporal contrast threshold was remeasured at $2 \mathrm{~Hz}$ to control for fatigue or practice effects. Each threshold determination was based on 35 stimulus trials, including 5 "empty" trials. The methods for adjusting stimulus level and data analysis were identical to those used for the luminance and chromatic threshold measurements.

The pattern reversal VEPs were measured monocularly. The stimulus was generated using a standard Medelec Sensor ST10, displayed on a Hitachi television screen and the responses to 64 reversals at $2 \mathrm{~Hz}$ were averaged using a Medelec Sensor EH94a averager (Honan et al. 1990). The field size subtended a visual angle of $12^{\circ}$ horizontal by $9^{\circ}$ vertical; the check size was $48 \mathrm{~min}$ arc. The luminance of the dark squares was $1.29 \log \mathrm{cd} \cdot \mathrm{m}^{-2}$ and the light squares was $2.86 \log$ $\mathrm{cd} \cdot \mathrm{m}^{-2}$. The Bjerrum screen visual fields were plotted using the technique described by Patterson and Heron (1980). The average screen luminance was $0.53 \mathrm{log}$ $\mathrm{cd} \cdot \mathrm{m}^{-2}$ and the luminance of the white targets was $2.25 \log \mathrm{cd} \cdot \mathrm{m}^{-2}$.

Colour vision was assessed clinically using the City University colour vision test (Keeler, 2nd edition, 1980) and the Farnsworth-Munsell 100-Hue test (Farnsworth 1943). The visual tests were undertaken in three separate sessions: the first containing the clinical examination, visual fields and VEPs; the second containing the luminance and chromatic threshold measurements and clinical colour vision tests; and the third session containing the de Lange attenuation characteristic determinations.

\section{Patients}

Fifteen patients with HMSN were included in the study. The clinical diagnosis of HMSN was based on the finding of distal weakness or amyotrophy, with or without pes cavus or sensory loss. Peripheral neuropathy was confirmed neurophysiologically in all cases. In cases with a known family history the diagnosis was straightforward. In the sporadic cases, all had clinical evidence of peroneal muscular atrophy and pes cavus. Other causes of peripheral neuropathy were excluded by appropriate biochemical tests. Sural nerve biopsy was not undertaken. Cases were classified using the Harding and Thomas (1980) criteria, in which patients with peroneal muscular atrophy and neurophysiological evidence of motor and sensory neuropathy were classified into HMSN type I and HMSN type II. Cases in which the median motor conduction velocity was less than $38 \mathrm{msec}^{-1}$ were put in type $I$ and cases in which the velocity was greater than $38 \mathrm{msec}^{-1}$ were put in type II. Eleven cases were classified as HMSN type I and 4 cases as HMSN type II. None of the cases had clinical evidence of central nervous system (CNS) involvement. Seven of the cases studied with HMSN 
Type I came from three unrelated families: 3 cases $(1,2,3)$ from one family, a mother with 2 sons, and 2 other families each with a mother and son (cases 4, 5: cases 7,12 ). All the other cases were obtained from separate families. There were 8 males and 7 females; the mean age was 31.5 years, SD 16.5 years, range 14-62 years. For the clinical and psychophysical measures a control group of healthy volunteers was matched for age; there were 7 males and 8 females. The results from the patient and age-matched control groups were analysed with paired $t$-tests; two-tailed probabilities were used throughout. For the analyses of individual cases, the upper limit of the normal range for the psychophysical measures was defined as the mean plus $2 \mathrm{SD}$ of the control group. A City University colour vision test result was considered abnormal if more than 2 errors occurred. The individual 100 -Hue test scores were considered abnormal if they were above published age-related normal values $(95 \%$ confidence levels) (Verriest et al. 1982). The normal range for the VEP P100 latency was the mean plus 2 SD from a separate control group, derived from 22 healthy volunteers aged between 20 and 69 years; the grouped data were analysed using an independent $t$-test with a pooled estimate of the variance.

\section{Results}

\section{Individual data analysis}

Results for the individual visual measures are shown in Table 1. Visual fields could not be plotted in three cases because the position of the blind spot could not be recorded consistently. None of the cases had pupil- lary abnormalities or evidence of pallor of the optic disc. Visual fields were abnormal in 4 cases; in each case the abnormality consisted of an arcuate scotoma. The clinical colour vision measurements showed no abnormal cases using the City test, whereas the Farnsworth-Munsell 100-Hue test score was elevated in 4 cases. No consistent polarity was observed in the cases with abnormal colour vision. The VEP was abnormal in 4 cases; in 2 cases $(5,6)$ the $P 100$ latency was prolonged; in case 8 there was a " $W$ " waveform, and case 9 had a very broad waveform; the P100 latency was normal in the latter 2 cases $(8,9)$. Luminance and chromatic thresholds and the de Lange attenuation characteristic were each abnormal in the same 3 cases $(4,9,12)$. Case 9 was the only patient with abnormal psychophysical and VEP measures, although the VEP abnormality consisted of a waveform disturbance rather than prolonged P100 latency; the visual field was also abnormal in this case but the 100-Hue test was normal. In all other cases there was patchy loss of function with very little overlap between the different visual measures.

\section{Group data analysis}

The mean VEP P100 latency of the HMSN group was $105 \mathrm{msec}$, $95 \%$ confidence intervals (CI) 100.7 109.3 msec. The mean P100 latency of the normal control group was $102.5,95 \% \mathrm{Cl} 99.3-105.7$. The mean difference between the two groups of $2.5 \mathrm{msec}$ was not significant $(t=1.03, d . f .=34$, NS). Results for the luminance and chromatic thresholds are shown in Fig. $1 \mathrm{a}$; the means and $95 \%$ CIs for the patient and control groups are presented. There was a small significant difference $(d)$ between the two groups for luminance

TABLE 1

SUMMARY OF INDIVIDUAL VISUAL RESULTS

\begin{tabular}{|c|c|c|c|c|c|c|c|c|c|c|c|c|}
\hline Case & $\begin{array}{l}\text { Age } \\
\text { (yrs) }\end{array}$ & $\begin{array}{l}\text { Near } \\
\text { acuity }\end{array}$ & $\begin{array}{l}\text { Snellen } \\
\text { acuity }\end{array}$ & $\begin{array}{l}\text { Pupil } \\
\text { action }\end{array}$ & $\begin{array}{l}\text { Optic } \\
\text { disc }\end{array}$ & $\begin{array}{l}\text { Visual } \\
\text { field }\end{array}$ & $\begin{array}{l}\text { HMSN } \\
\text { type }\end{array}$ & $\begin{array}{l}\text { City } \\
\text { test }\end{array}$ & $\begin{array}{l}\text { 100-Hue } \\
\text { test }\end{array}$ & VEP & $\begin{array}{l}\text { Lum/ } \\
\text { Chrom }\end{array}$ & de Lange \\
\hline 1 & 19 & $\mathrm{~N} 4,5$ & $6 / 6$ & - & - & + & I & - & - & 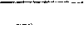 & - & 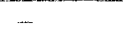 \\
\hline 2 & 15 & $\mathrm{~N} 4,5$ & $6 / 6$ & - & - & $*$ & I & - & + & $\ldots$ & $\ldots$ &.- \\
\hline 3 & 39 & $\mathrm{~N} 4,5$ & $6 / 6$ & - & -- & : & I & - & - & & ... & - \\
\hline 4 & 62 & $\mathrm{~N} 12$ & $6 / 9$ & $\cdots$ & - & - & I & & $\ldots$ & & + & + \\
\hline 5 & 36 & $\mathrm{~N} 4,5$ & $6 / 6$ & - & - & & I & $\ldots$ & $\cdots$ & + & $\ldots$ & ... \\
\hline 6 & 17 & $\mathrm{~N} 4,5$ & $6 / 4$ & - & - & + & 1 & $\cdots$ & - & + & $\ldots$ & - \\
\hline 7 & 61 & N5 & $6 / 9$ & - & - & & I & $\cdots$ & -- & .. & & -. \\
\hline 8 & 35 & $\mathrm{~N} 4,5$ & $6 / 5$ & - & - & + & II & - & - & + & - & - \\
\hline 9 & 24 & $\mathrm{~N} 4,5$ & $6 / 9$ & - & - & + & II & $\cdots$ & - & + & + & i \\
\hline 10 & 21 & N5 & $6 / 6$ & - & $\ldots$ & -- & I & -- & + & - & $\cdots$ & - \\
\hline 11 & 14 & N5 & $6 / 9$ & $\ldots$ & - & * & 1 & $\cdots$ & + & $*$ & & $\ldots$ \\
\hline 12 & 49 & N5 & $6 / 6$ & - & - & - & 1 & - & - & $\cdots$ & + & + \\
\hline 13 & 20 & N5 & $6 / 6$ & - & - & + & II & -- & + & $\ldots$ & - & $\cdots$ \\
\hline 14 & 44 & N8 & $6 / 9$ & - & - & -- & 1 & - & - & - & $\ldots$ & -- \\
\hline 15 & 16 & $\mathrm{~N} 4,5$ & $6 / 5$ & - & - & $\ldots$ & II & $\cdots$ & - & - & $\cdots$ & $*$ \\
\hline
\end{tabular}

${ }^{+}=$abnormal result, $-=$normal result, $*=$ no result recorded. HMSN $=$ hereditary motor and sensory neuropathy; VEP $=$ visual evoked potential; Lum/Chrom = luminance and chromatic threshold; de Lange $=$ de Lange attenuation characteristic 


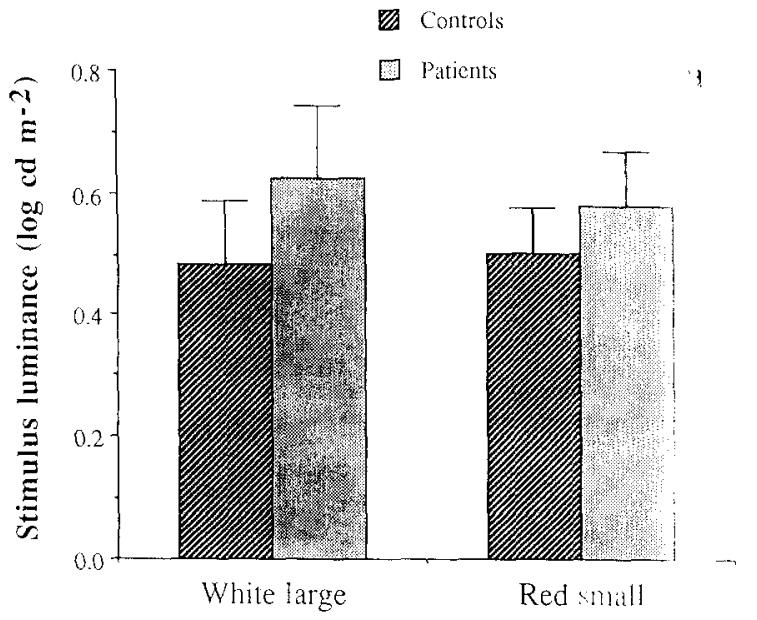

Threshold condition

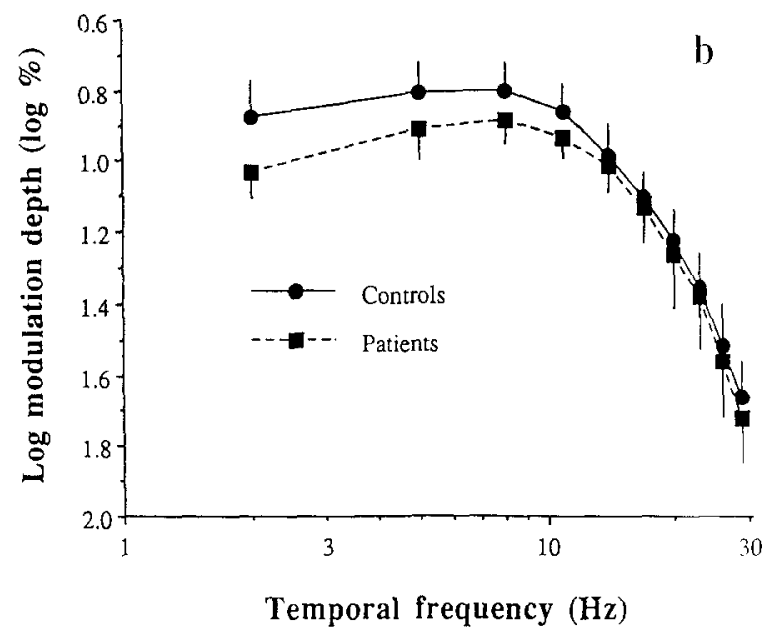

Fig. 1 a: luminance and chromatic threshold results. The means and 95\% confidence intervals for patient and control groups under the two stimulus conditions are shown. b: de Lange attenuation characteristic results. The means and $95 \%$ confidence intervals for patient and control groups at each temporal frequency are shown.

threshold (white large, $d=0.14 \log \mathrm{cd} \cdot \mathrm{m}^{-2}, t=2.20$, d.f. $=14, P<0.05$ ), but not for chromatic threshold (red small, $d=0.08 \log \mathrm{cd} \cdot \mathrm{m}^{-2}, t=1.58$, d.f. $=14$, NS). Also the difference between the group scores for the 100 -Hue test was not significant $(d=85, t=2.05$, d.f. $=14$, NS). The results for the de Lange attenuation characteristic are shown in Fig. 1b; the means and 95\% CI for the patient and control groups are presented. There was a significant reduction in temporal contrast sensitivity at low temporal frequencies $(2 \mathrm{~Hz}$, $d=0.15 \log$ percent, $t=3.17$, d.f. $=13, P<0.01$ ). At mid temporal frequencies the difference was smaller $(11 \mathrm{~Hz}, d=0.08 \log$ percent, $t=2.56, d . f .=13, P<$ 0.05 ) and at high temporal frequencies the small differences were not significant $(29 \mathrm{~Hz}, d=0.04$ log percent, $t=0.85$, d.f. $=12$, NS). The magnitude of the low temporal-frequency loss was confirmed by the repeat 2 $\mathrm{Hz}$ measurement done routinely at the end of each experiment. This repeat measurement showed a mean reduction of temporal contrast sensitivity in the patient group relative to the control group of again $0.15 \mathrm{log}$ percent $(t=3.28, d . f .=13, P<0.01)$.

\section{Discussion}

The analysis of individual patient data revealed a low proportion of abnormalities associated with each individual visual measure. The proportion of cases, 2/15 (13\%), with delayed VEP P100 latencies was similar to that found by Bird and Griep (1981) and less than those reported by Tackmann and Radu (1980) and Carroll et al. (1983). It should be emphasised that none of the patients in this study had clinical evidence of CNS involvement. The proportion of abnormal individual psychophysical and VEP measures was similar, although there was little overlap in the distribution of individual abnormalities in psychophysical, VEP, visual field and other clinical visual measurements. This finding of patchy visual loss in individual cases was similar to that of Carroll et al. (1983) and to that in individual cases of MS without a clinical history of optic neuritis (Honan et al. 1990).

The group analysis result indicating no significant mean difference in VEP latency between control and HMSN groups was consistent with Gjerstad et al.'s (1988) findings from their whole patient group. They reported that VEP latency was significantly prolonged in HMSN type I relative to HMSN type II. However, in the present series, the small number of cases with HMSN type II did not allow meaningful separate statistical analysis (this is the subject of an ongoing study). The group analysis of the psychophysical measures provided evidence of loss of function both for luminance sensitivity and for temporal contrast sensitivity at low temporal frequencies.

The type of visual loss in HMSN was different from that found in MS. In HMSN, losses in luminance sensitivity were greater than those in chromatic sensitivity; whereas in MS either an approximately equal foveal reduction of luminance and chromatic threshold (Foster et al. 1985; Honan et al. 1990), or a greater loss of chromatic sensitivity (Fallowfield and Krauskopf 1984; Mullen and Plant 1986) have been reported. For temporal contrast sensitivity, the losses in HMSN occurred predominantly at low temporal frequencies and decreased at mid and high temporal frequencies. In MS, losses in temporal contrast sensitivity have been reported at all temporal frequencies, although the magnitude of the loss may be less at high temporal frequencies (Plant and Hess 1983; Edgar et al. 1990; Honan et al. 1990).

When considered in terms of the spatial and temporal filter properties of the visual pathway, the differ- 
ences in the effects of HMSN and MS on visual function may be interpreted with respect to a single, low temporal frequency, high spatial frequency channel (Hess and Plant 1985). In MS, a general loss in sensitivity of this channel has been proposed (Plant and Hess 1985, Edgar et al. 1990). In HMSN, we suggest a partial loss in sensitivity of this channel, confined to high spatial frequencies. Such a loss would account for both the greater low temporal frequency losses in modulation sensitivity (Fig. 1b) and the greater detection threshold losses in the large-auxiliary-field conditions (Fig. 1a), where spatial transients (high spatial frequencies) would normally assist detection performance (Foster 1986).

The pathophysiology of the visual pathways in HMSN has not been fully established. Therefore, the precise explanation for the psychophysical differences between HMSN and MS observed here remains undetermined. It is clear, however, that the CNS pathology in HMSN is distinct from that in MS (Alajouanine et al. 1967; Hughes and Brownwell 1972; Weller 1985).

\section{References}

Alajouanine, T., Castaigne, P., Cambier, J. and Escourolle, R. (1967) Maladie de Charcot-Marie. Etude anatomo-clinique d'une observation suivie pendant 65 ans, Presse Med., 75: 2745-2750.

Bird, T.D. and Griep, E. (1981) Pattern reversal visual evoked potentials. Studies in Charcot-Marie-Tooth hereditary neuropathy, Arch. Neurol,, 38: 739-741.

Brust, J.C.M., Lovelace, R.E. and Devi, S. (1978) Clinical and electrodiagnostic features of Charcot-Marie-Tooth syndrome, Acta Neurol. Scand., 58 (Suppl. 68): 1-142.

Carroll, W.M., Jones, S.J. and Halliday, A.M. (1983) Visual evoked potential abnormalities in Charcot-Marie-Tooth disease and comparison with Friedreich's ataxia, J. Neurol. Sci., 61: 123-133.

De Recondo, J. (1975) Hereditary neurogenic muscular atrophies (Charcot-Marie-Tooth disease). In: P.J. Vinken and G.W. Bruyn (Eds.), Handbook of Clinical Neurology, Vol. 21, North-Holland, Amsterdam, pp. 271-317.

Edgar, G.K., Foster, D.H., Honan, W.P., Heron, J.R. and Snelgar, R.S. (1990) Optic neuritis: variations in temporal modulation sensitivity with retinal eccentricity, Brain, 113: 487-496.

Fallowfield, L. and Krauskopf, J. (1984) Selective loss of chromatic sensitivity in demyelinating disease, Invest. Ophthalmol. Vis. Sci., 25: $771-773$.

Farnsworth, D. (1943) The Farnsworth-Munsell 100-Hue and dichotomous tests for color vision, J. Opt. Soc. Am., 33: 568-578.

Foster, D.H. (1981) Changes in field spectral sensitivities of red-, green- and blue-sensitive colour mechanisms obtained on small background fields, Vision Res., 21: 1433-1455.
Foster, D.H. (1986) Psychophysical loss in optic neuritis: luminance and colour aspects. In: R.F. Hess and G.T. Plant (Eds.). Optic Neuritis, Cambridge University Press, Cambridge, pp, 152-191.

Foster, D.H. and Bischof, W.F. (1987) Bootstrap variance estimators for the parameters of small-sample sensory-performance functions, Biol. Cybern., 57: 314-347.

Foster, D.H. and Snelgar, R.S. (1983) Test and field spectral sensitivities of colour mechanisms obtained on small white backgrounds: action of unitary opponent-colour processes?, Vision Res, 23: $787-797$.

Foster, D.H., Snelgar, R.S. and Heron, J.R. (1985) Nonselective losses in foveal chromatic and luminance sensitivity in multiple sclerosis, Invest. Ophthalmol. Vis. Sci., 26: 1431-1441.

Gjerstad, L., Nyberg-Hansen, R. and Ganes, T. (1988) Visual evoked responses in hereditary motor and sensory neuropathies, Acta Neurol. Scand., 77: 215-219.

Hall, J.L. (1981) Hybrid adaptive procedure for estimation of psychometric functions, J. Acoust. Soc. Am., 69: 1763-1769.

Harding, A.E. and Thomas, P.K. (1980) The clinical features of hereditary motor and sensory neuropathy types I and II, Brain, 103: $259-280$.

Hess, R.F. and Plant, G.T. (1983) The effect of temporal frequency variation on threshold contrast sensitivity deficits in optic neurjtis, J. Neurol. Neurosurg. Psychiat., 46: 322-330.

Hess, R.F, and Plant, G.T. (1985) Temporal frequency discrimination in human vision: evidence for an additional mechanism in the low spatial and high temporal frequency region, Vision Res., 25: 1493-1500.

Honan, W.P., Heron, J.R., Foster, D.H., Edgar, G.K., Scase, M.O. and Collins, M.F. (1990) Visual loss in multiple sclerosis and its relation to previous optic neuritis, disease duration, and clinical classification, Brain, 113: $975-98$ ?

Hoyt, W.F. (1960) Charcot-Marie-Tooth disease with primary optic atrophy, Arch. Ophthalmol., 64: 925-928.

Hughes, T.J. and Brownwell, B. (1972) Pathology of peroneal muscular atrophy (Charcot Marie Tooth disease), J. Neurol. Neurosurg. Psychiat., 35: 648-657.

Mullen, K.T. and Plant, G.T. (1986) Colour and luminance vision in human optic neuritis, Brain, 109: 1 13.

Patterson, V.H. and Heron, J.R. (1980) Visual field abnormalities in multiple sclerosis, J. Neurol. Neurosurg. Psychiat., 43: 205-209.

Plant, G.T. and Hess, R.F. (1985) Temporal frequency discrimination in optic neuritis and multiple sclerosis, Brain, 108: 647-676.

Schneider, D.E. and Abeles, M.M. (1937) Charcot-Marie-Tooth disease with primary optic atrophy, J. Nerv. Ment. Dis., 30: 354-359.

Tackmann, W. and Radu, E.W. (1980) Pattern shift visual evoked potentials in Charcot-Marie-Tooth disease, HMSN, type 1, J. Neurol., 224: 71-74.

Taylor, M.M. and Creelman, C.D. (1967) PEST: Efficient estimates on probability functions, J. Acoust. Soc. Am., 41: 782-787.

Verriest, G., Van Laethem, J. and Uvijls, A. (1982) A new assessment of the normal ranges of the Farnsworth-Munsell 100-Hue test, Am J Ophthalmol., 93: 635--642.

Weller, R.O. (1985) Pathology of multiple sclerosis, In: WB Matthews (Ed.), McAlpine's Multiple Sclerosis, Churchill Livingstone, Edinburgh, pp. 301-343. 